\title{
Effect of hyperoside on the apoptosis of A549 human non-small cell lung cancer cells and the underlying mechanism
}

\author{
YU YANG, JICHENG TANTAI, YIFENG SUN, CHENXI ZHONG and ZHIGANG LI \\ Department of Thoracic Surgery, Shanghai Chest Hospital Affiliated to Shanghai \\ Jiao Tong University, Shanghai 200030, P.R. China
}

Received December 4, 2015; Accepted November 29, 2016

DOI: $10.3892 / \mathrm{mmr} .2017 .7453$

\begin{abstract}
Hyperoside (HY) is a major pharmacologically active component from Prunella vulgaris L. and Hypericum perforatum. The present study aimed to determine the anticancer effect of HY and determine the underlying mechanisms involved. Human A549 cells were treated with HY (10,50 and $100 \mu \mathrm{M}$ ), and cell viability was detected by an MTT assay. Cell apoptosis and mitochondrial membrane potential were determined by flow cytometry. Western blot analysis was used to identify the expression of apoptosis-associated proteins and phosphorylation of MAPK. The present study demonstrated that HY significantly inhibited the viability of A549 cells in a time- and dose-dependent manner, and enhanced the percentage of apoptotic cells. HY also significantly increased the protein phosphorylation of p38 mitogen-activated protein kinase (MAPK) and c-Jun N-terminal kinase (JNK), disrupted mitochondrial membrane penetrability, and triggered the release of mitochondrial cytochrome $c$ and apoptosis-inducing factor into the cytosol. Treatment with HY also activated the expression of caspase- 9 and caspase-3. These results suggested that HY-induced apoptosis was associated with activation of the p38 MAPK- and JNK-induced mitochondrial death pathway. HY may offer potential for clinical applications in treating human non-small cell lung cancer and improving cancer chemotherapy.
\end{abstract}

\section{Introduction}

Lung cancer, characterized by high incidence and mortality rates, is a malignant tumor, which threatens human health. It is reported that the incidence and mortality rates have increased significantly in several countries in the last 50 years $(1,2)$. The etiology of lung cancer remains to be fully elucidated,

Correspondence to: Dr Zhigang Li, Department of Thoracic Surgery, Shanghai Chest Hospital Affiliated to Shanghai Jiao Tong University, 241 West Huaihai Road, Shanghai 200030, P.R. China E-mail: lizhigang20151112@126.com

Key words: hyperoside, non-small cell lung cancer, apoptosis, mitochondria and there is substantial data showing a close association between long-term heavy smoking and the occurrence of lung cancer (2). Non-small cell lung cancer (NSCLC) accounts for $\sim 80 \%$ of all lung cancer cases, and $\sim 75 \%$ of patients are diagnosed in the middle-late stage $(3,4)$. Therapies for NSCLC include surgery, radiation and chemotherapy; however, the 5-year survival rate remains low. In addition, the side effects and pain from treatment cause substantial physical and mental trauma to patients. In previous years, the screening of compounds from medicinal plants for the treatment of various diseases has received increased attention. For example, the anticancer drug, paclitaxel (Taxol), obtained from Taxus species has been extensively investigated for several years (5). Therefore, obtaining anticancer compounds from medicinal plants is important in cancer treatment.

Hyperoside (HY; Fig. 1) is a major pharmacologically active component from Prunella vulgaris L. and Hypericum perforatum, which exerts a wide variety of biological activities, including antioxidant, antihyperglycemic, anticancer, anti-inflammatory and cardiovascular protective effects (6-9). However, the underlying molecular mechanisms remain to be fully elucidated. The present study aimed to determine the anticancer effect of HY and identifying the possible mechanism involved. In the present study, HY was identified as an anticancer agent, which induced the apoptosis of human NSCLC A549 cells though the mitochondria apoptotic pathway.

\section{Materials and methods}

Cell culture. A549 cells were obtained from the Shanghai Cell Bank, Chinese Academy of Sciences (Shanghai, China). The cells were cultured in DMEM (Invitrogen; Thermo Fisher Scientific, Inc., Waltham, MA, USA) supplemented with $10 \%$ fetal bovine serum (FBS; Invitrogen; Thermo Fisher Scientific, Inc.), $100 \mathrm{U} / \mathrm{ml}$ penicillin and $100 \mu \mathrm{g} / \mathrm{ml}$ streptomycin, and incubated in a humidified atmosphere at $37^{\circ} \mathrm{C}$ with $5 \% \mathrm{CO}_{2}$.

HY preparation. HY with a purity of $98.78 \%$ was obtained as a canary yellow needle-shaped crystal (YUANYE Technological Co. Ltd., Shanghai, China). It was dissolved in an appropriate volume of dimethylsulfoxide (DMSO) and diluted to the desired concentrations $(10,50$ and $100 \mu \mathrm{M})$ prior to utilization, with the final concentration of DMSO maintained below $0.5 \%$. 
Cell viability. A standard tetrazolium bromide (MTT) assay was used to assess cell viability. Briefly, the cells $\left(5 \times 10^{3}\right.$ cells/well) were seeded in 96 -well plates. Following treatment with $\mathrm{HY}(0,10,50$ and $100 \mu \mathrm{M})$ for $24 \mathrm{~h}$ at $37^{\circ} \mathrm{C}$, $50 \mathrm{ml}$ of MTT (Sigma-Aldrich; Merck Millipore, Darmstadt, Germany) solution ( $2 \mathrm{mg} / \mathrm{ml}$ in PBS) was added to each well and the plates were incubated for an additional $4 \mathrm{~h}$ at $37^{\circ} \mathrm{C}$. The medium was then removed and the cells were incubated with $200 \mu \mathrm{l}$ DMSO in the dark for $30 \mathrm{~min}$ at $37^{\circ} \mathrm{C}$ to dissolve violet crystals. The absorbance was read at $570 \mathrm{~nm}$ on an automatic microplate reader with DMSO as the blank control. All assays were performed with five replicates and repeated at least three times.

Cell apoptosis. In order to determine cell apoptosis, $5 \times 10^{4}$ cells were trypsinized, washed with cold phosphate-buffered saline (PBS) and resuspended in binding buffer according to the manufacturer's protocol of the Annexin V-fluorescein isothiocyanate (FITC)/propidium iodide (PI) Apoptosis Detection kit (cat. no. KGA106; Nanjing KeyGen Biotech Co., Ltd., Nanjing, China). FITC-Annexin V and PI were added to the fixed cells for $20 \mathrm{~min}$ in darkness at room temperature. Subsequently, Annexin V binding buffer was added to the mixture prior to quantifying the fluorescence using a FACSort flow cytometer (BD Biosciences, Franklin Lakes, NJ, USA). Cell apoptosis was analyzed using Cell Quest version 3.0 (BD Biosciences).

Mitochondrial membrane potential (MMP). Rhodamine-123 (Rho-123) dye (Sigma-Aldrich; Merck Millipore) was used to detect alterations in MMP. The cells $\left(5 \times 10^{4}\right.$ cells/well) were cultured in a 24-well plate. Following treatment with HY (0, $10,50$ and $100 \mu \mathrm{M})$ for $24 \mathrm{~h}$, the cells were washed with PBS, incubated with Rho- $123(10 \mathrm{mg} / \mathrm{ml})$ for $30 \mathrm{~min}$ at $37^{\circ} \mathrm{C}$ and subsequently subjected to flow cytometry.

Separation of mitochondrial and cytosolic fractions. A mitochondria/cytosol fractionation kit (Abcam, Cambridge, UK) was used to prepare the mitochondrial and cytosolic fractions from the cells, in accordance with the manufacturer's protocol. Following treatment for $12 \mathrm{~h}$ with the different concentrations of HY, the cells were harvested, washed by PBS and centrifuged at $600 \mathrm{x}$ g for $5 \mathrm{~min}$ at $4^{\circ} \mathrm{C}$. Following re-suspension with cytosolic extraction buffer, the cells were homogenized on ice for 40 passes with a grinder for $10 \mathrm{~min}$. The homogenate was subsequently centrifuged at $700 \mathrm{x}$ g for $10 \mathrm{~min}$ at $4^{\circ} \mathrm{C}$, supernatant was carefully collected, and the sediment was saved. Following centrifugation at $10,000 \mathrm{x} \mathrm{g}$ for $30 \mathrm{~min}$ at $4^{\circ} \mathrm{C}$, the supernatant was collected as the cytosolic fraction and stored at $-80^{\circ} \mathrm{C}$. The sediment was re-suspended with mitochondrial extraction buffer, vortexed and stored as the mitochondrial fraction at $-80^{\circ} \mathrm{C}$.

Western blot analysis. The cultured cells were harvested and washed twice with PBS, and lysed in ice-cold radioimmunoprecipitation assay buffer (Beyotime Institute of Biotechnology, Shanghai, China) with freshly added $0.01 \%$ protease inhibitor cocktail (Sigma-Aldrich; Merck Millipore) and incubated on ice for $30 \mathrm{~min}$. The cell lysate was centrifuged at $13,000 \times \mathrm{g}$ for $10 \mathrm{~min}$ at $4^{\circ} \mathrm{C}$, following

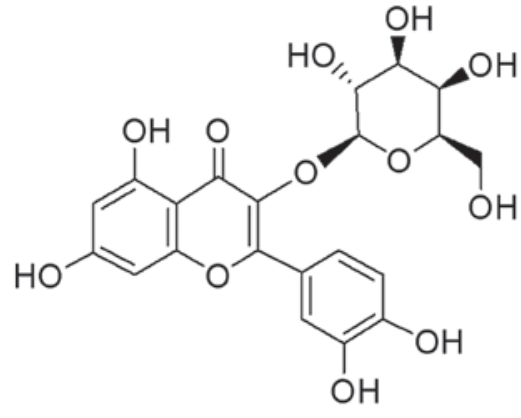

Figure 1. Chemical structure of hyperoside.



Figure 2. HY inhibits the proliferation of A549 cells. Following treatment with HY $(10,50$ and $100 \mu \mathrm{M})$ for 12,24 and $48 \mathrm{~h}$, cell viability was detected using tetrazolium bromide. Data are presented as the mean \pm standard deviation $(n=6) .{ }^{* *} \mathrm{P}<0.01$, compared with the control group. HY, hyperoside; OD, optical density.

which the supernatant was run on a $10 \%$ SDS-PAGE gel and transferred electrophoretically onto a polyvinylidene fluoride membrane (EMD Millipore, Billerica, MA, USA). The blots were blocked with $5 \%$ skim milk, followed by incubation with antibodies against phosphorylated $(\mathrm{P})$-c-Jun N-terminal kinase (P-JNK; cat. no. ab4821; 1:500; Abcam), JNK (cat. no. ab154902; 1:200; Abcam), P-P38 (cat. no. ab47363; 1:500; Abcam), P38 (cat. no. ab170099; 1:1,000; Abcam), GAPDH (cat. no. ab9485; 1:2,500; Abcam), apoptosis-inducing factor (AIF; cat. no. ab1998; 1:500; Abcam), cytochrome $c$ (cat. no. ab13575; 1:500; Abcam), caspase-3 (cat. no. ab2171; 1:500; Abcam) and caspase-9 (cat. no. ab32539, 1:1,000; Abcam) at $4^{\circ} \mathrm{C}$ overnight. The blots were then incubated with goat anti-mouse or anti-rabbit secondary antibody (Beyotime Institute of Biotechnology, Shanghai, China) at room temperature for $1 \mathrm{~h}$ and visualized using SuperSignal West Dura Extended Duration substrate (Thermo Fisher Scientific, Inc.) and detected using a DNR Bio-Imaging System (DNR Bio-Imaging Systems, Ltd., Jerusalem, Israel). Protein density levels were determined by Image Analysis software version 4.0.3.2 (Scion Co., Ltd., Frederick, MD, USA) and the densitometric analysis of blots from three experiments.

Statistical analysis. All results are presented as the mean \pm standard deviation and the data were analyzed using the SPSS 13.0 statistical package (SPSS, Inc., Chicago, IL, USA). Data for multiple comparisons were subjected to one-way analysis of 

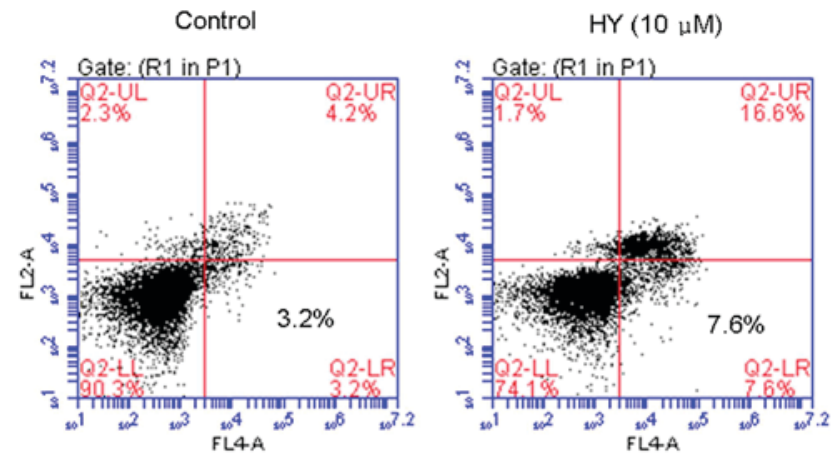

$\mathrm{HY}(50 \mu \mathrm{M})$

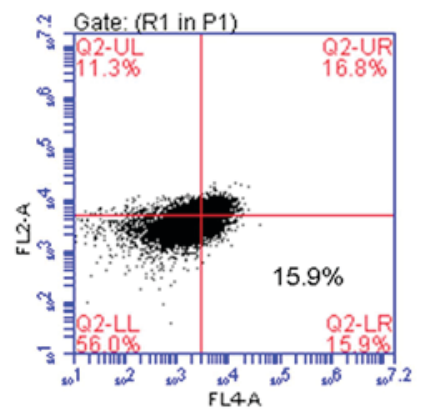

HY $(100 \mu \mathrm{M})$
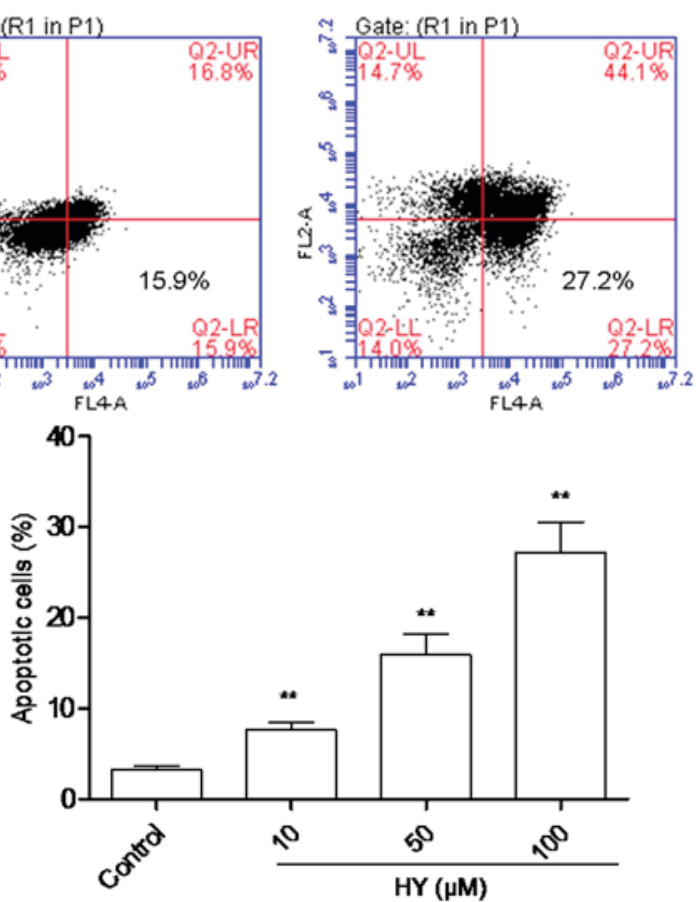

Figure 3. HY induces apoptosis of human A549 cells. The A549 cells were treated with HY $(0,10,50$ and $100 \mu \mathrm{M})$ for $24 \mathrm{~h}$ and cell apoptosis was assessed using flow cytometry. Data are presented as the mean \pm standard deviation $(n=6) .{ }^{* *} \mathrm{P}<0.01$, compared with the control group. HY, hyperoside. The lower left quadrant shows viable cells, which are negative for both AV and PI. The lower right quadrant displays early apoptotic cells, which are positive for AV and negative for PI. The upper right quadrant represents late apoptotic cells, which are positive for both AV and PI. The upper left quadrant indicates the cells damaged during the procedure. AV, Annexin V; PI propidium iodide.

variance followed by Dunnett's test. $\mathrm{P}<0.05$ was considered to indicate a statistically significant difference.

\section{Results}

HY suppresses the viability of A549 cells. Following treatment of the cells with various concentrations of $\mathrm{HY}(0,10,50$ and $100 \mu \mathrm{M}$ ) for 12,24 and $48 \mathrm{~h}$, cell viability was determined using an MTT assay. As shown in Fig. 2, HY inhibited the viability of the A549 cells in a time- and dose-dependent manner. Cell proliferation was markedly decreased, compared with that in the control group.

$H Y$ induces the apoptosis of cells. In order to quantify cellular apoptosis, a flow cytometric assay was performed to analyze
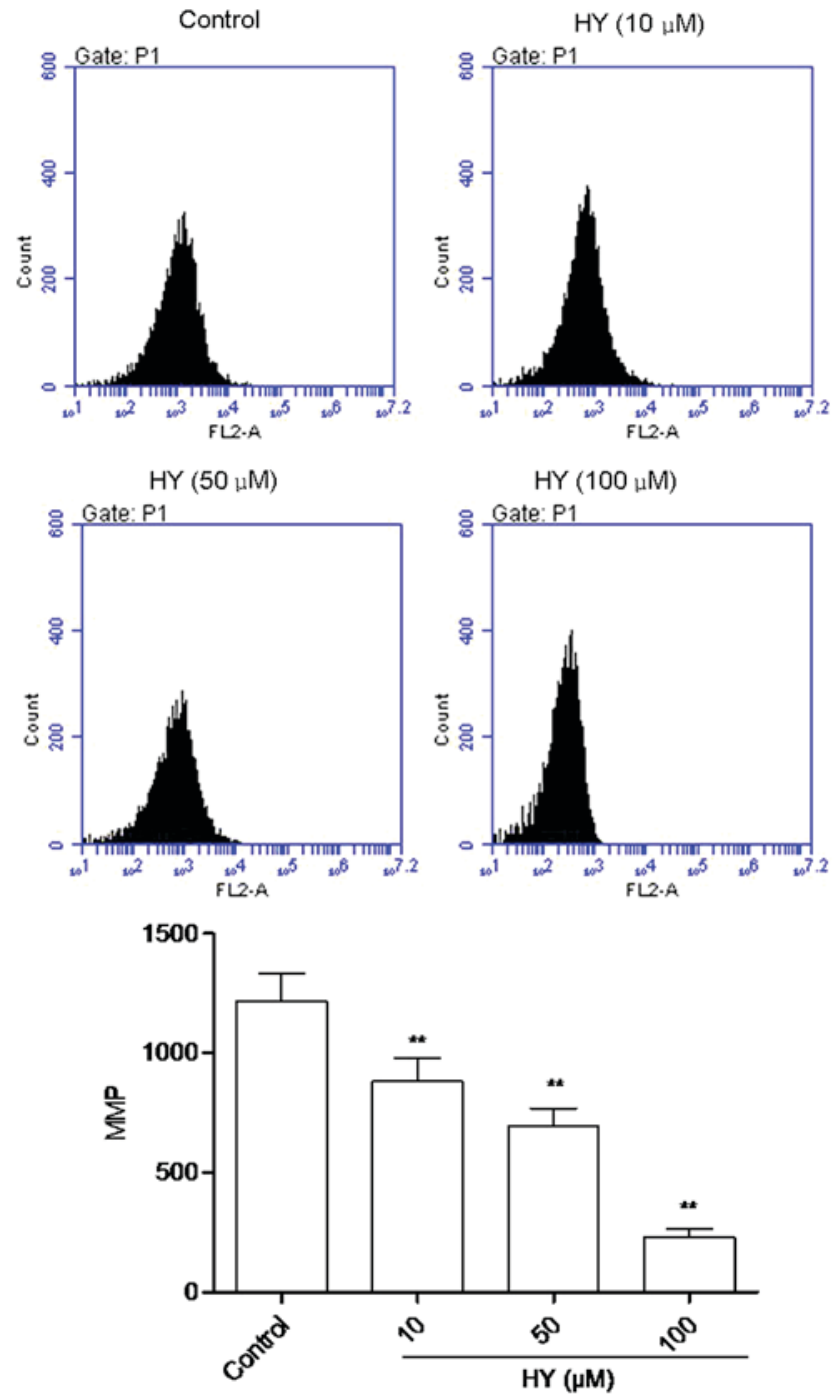

Figure 4. HY enhances MMP dissipation. MMP was identified by the fluorescent intensity of rhodamine 123 following treatment with $\mathrm{HY}(0,10,50$ and $100 \mu \mathrm{M}$ ) treatment for $24 \mathrm{~h}$. Data was presented as the mean \pm standard deviation $(\mathrm{n}=6) .{ }^{* *} \mathrm{P}<0.01$, compared with the control group. HY, hyperoside; MMP, mitochondrial membrane potential.

the proportion of apoptotic cells dyed with PI and Annexin V, to enable evaluation of the integrity of cell membrane and the externalization of phosphatidylserine. As shown in Fig. 3, analysis of the cell population revealed distinct sets within the population. The majority of cells were alive in the control group (Fig. 3). However, when the cells were incubated with various concentrations of HY for $24 \mathrm{~h}$, there was a notable increase in the percentage of apoptotic cells, and this occurred in a dose-dependent manner.

HY enhances MMP dissipation. The fluorescent intensity (FI) of Rho123 is positively correlated with the MMP. As shown in Fig. 4, high intensity fluorescence was visible in the control group of cells. Following HY treatment for 24 h, FI decreased in a dose-dependent manner.

HY induces the release of cytochrome $c$ and AIF. Following MMP dissipation, the key event of mitochondria-dependent apoptosis is the release of mitochondrial cytochrome $c$ 
A
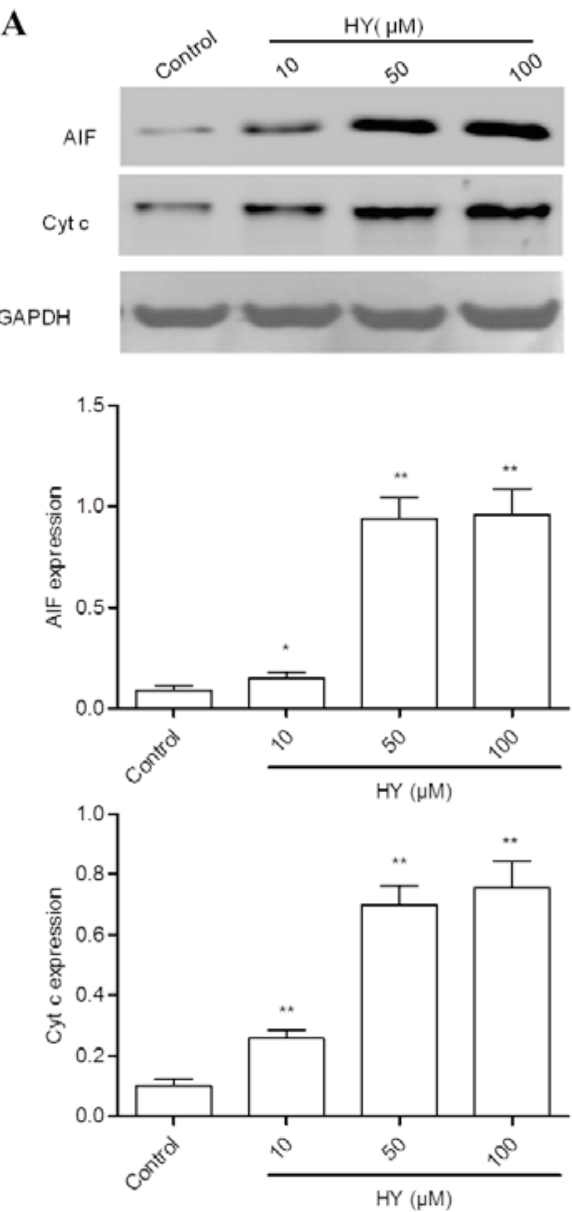

B
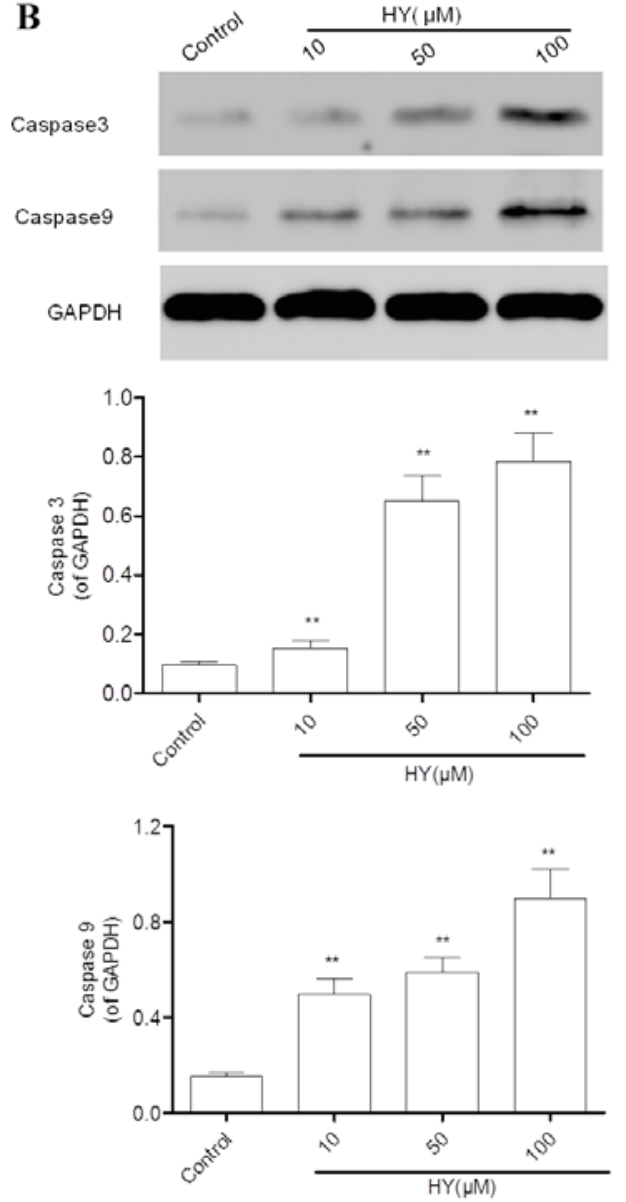

Figure 5. Effects of HY on the protein expression of Cyt c, AIF, caspase-3 and caspase-9. (A) A549 cells treated with HY (0, 10, 50 and $100 \mu \mathrm{M})$ for $12 \mathrm{~h}$. The cytosolic fractions of cells were prepared and the protein expression of levels of Cyt $\mathrm{c}$ and AIF were analyzed using western blot analysis, with GAPDH used as a loading control. (B) Expression levels of caspase-3 and caspase-9 were detected using western blot analysis. Data are presented as the mean \pm standard deviation $(\mathrm{n}=3) .{ }^{* *} \mathrm{P}<0.01$, compared with the control group. HY, hyperoside; Cyt c, cytochrome $c$; AIF, apoptisis-inducing factor.

A
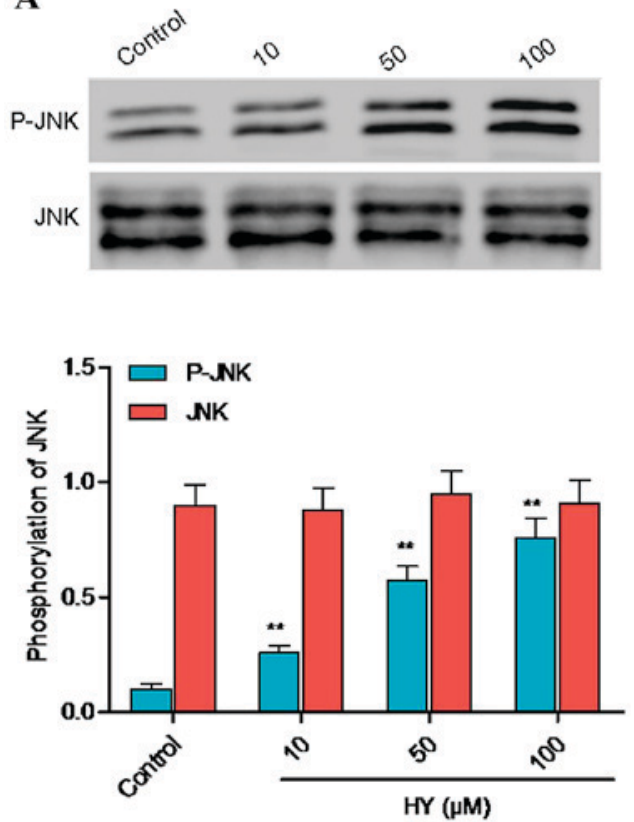

B
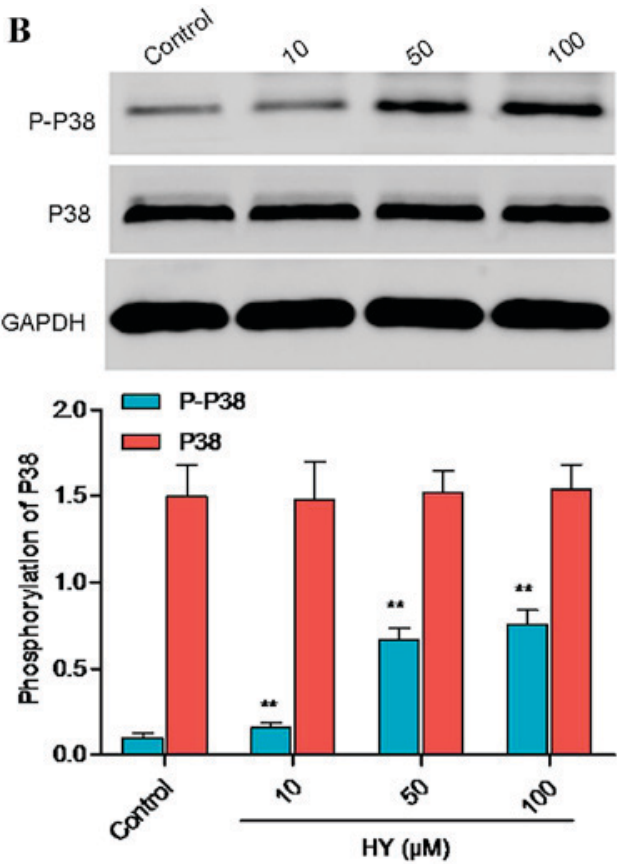

Figure 6. HY inhibits JNK and p38 signaling. A549 cells were treated with HY (10, 50, and $100 \mu \mathrm{M})$ for 3 h. Protein levels of (A) P-JNK, JNK, (B) P-p38 and p38 were identified using western blot analysis. GAPDH was used as a loading control. Data are presented as the mean \pm standard deviation $(\mathrm{n}=3)$. "P<0.05, ${ }^{* *} \mathrm{P}<0.01$, compared with the control group. HY, hyperoside; JNK, and c-Jun N-terminal kinase; P-, phosphorylated. 
and AIF into cytosol. Therefore, these two parameters were evaluated using western blot analysis. The results revealed that the expression levels of cytochrome $c$ and AIF (Fig. 5A) were lower in the control group of cells, and were significantly elevated by HY treatment for $24 \mathrm{~h}$.

HY activates caspase-3 and caspase-9. Caspase-3, a common downstream apoptosis effector, can be activated by caspase- 9 or caspase- 8 and cleaved into the active fragment. In the present study, the protein expression levels of caspase- 3 and caspase- 9 were detected using western blot analysis. The expression levels of caspase-3 and caspase- 9 in the control group were low (Fig. 5B). However, treatment with HY for $12 \mathrm{~h}$ elevated their expression levels in a dose-dependent manner.

HY facilitates protein phosphorylation of p38 mitogen-activated protein kinase (MAPK) and JNK. Cell apoptosis is closely associated with activation of the JNK and p38 MAPK signaling pathways, which is characterized by increased protein phosphorylation of p38 MAPK and/or JNK. Following treatment with $\mathrm{HY}$ for $3 \mathrm{~h}$, the protein phosphorylation levels of p38 MAPK and JNK were analyzed using western blot analysis (Fig. 6A and B). Treatment with $\mathrm{HY}$ for $3 \mathrm{~h}$ increased the protein phosphorylation of p38 MAPK and JNK, and there were significant differences between the HY-treated groups and the control group.

\section{Discussion}

Higher plants produce an abundance of substances, which have been a reliable source of pharmaceuticals. In the present study, it was found that HY effectively inhibited the proliferation of human NSCLC A549 cells in a dose- and time-dependent manner. Furthermore, Annexin V/PI staining revealed that treatment with HY $(10,50$ and $100 \mu \mathrm{M})$ for $12 \mathrm{~h}$ increased the percentage of apoptotic cells in a dose-dependent manner. These results indicated that HY induced apoptosis of the A549 cells.

MAPK pathways are generally recognized as the signal transducers of apoptosis in tumor cells, closely associated with responses to extracellular stimuli, including small molecular compounds (10-13). It is known that the MAPK system is composed of extracellular signal-regulated kinases, JNK and p38 MAP kinase. The JNK and p38 MAPK pathways can be activated by genotoxic agents and by the cytokine-mediating stress response, inducing growth inhibition and apoptosis in the cells (14). The induction of A549 cell apoptosis by 2-methoxy-1,4-naphthoquinone (MNQ) is independent of cell cycle arrest, and is mediated by the JNK and p38 MAPK signaling pathways. These signaling pathways have been found to be stimulated by oxidative DNA damage caused by the increased generation of reactive oxygen species (ROS) in the MNQ-treated A549 cells (14). It has been reported that capsaicin induces SMMC-7721 cell apoptosis through the generation of intracellular ROS, dissipation of MMP, and activation of the JNK and p38 MAPK pathways (15). Based on the above evidence, it is clear that p38 MAPK and JNK pathways are crucial in tumor cell apoptosis. In the present study, western blot analysis was used to identify the phosphorylation of p38 MAPK and JNK. The results revealed that HY significantly increased the phosphorylation levels of p38 MAPK and JNK, indicating the simultaneous activation of these two signaling pathways.

Activation of the intrinsic mitochondrial pathway can elicit the release of several apoptotic factors, including cytochrome $c$ and AIF, which results in mitochondrial apoptosis and activates the mitochondrial apoptotic pathway. The release of cytochrome $c$ facilitates the formation of the apoptosome-containing adaptor, apoptotic protease-activating factor-1, and another initiator, caspase-9, in the presence of dATP, following which caspase-3 is activated leading to cell apoptosis $(16,17)$. AIF can elicit cell apoptosis independently of the activation of caspase-3 (18). The enhanced protein expression of activated caspase-3, a downstream effector caspase, indicated that HY triggered caspase-dependent apoptosis, which can be activated by the mitochondrial apoptotic pathway and/or the death receptor pathway. The present study also found that $\mathrm{HY}$ facilitated the loss of MMP, and the release of cytochrome $c$ and AIF into the cytosol, and enhanced the protein expression of caspase-9. This indicated that HY induced apoptosis of the A549 cells via the mitochondrial apoptotic pathway.

In conclusion, the present study demonstrated that HY elevated the protein phosphorylation levels of p38 MAPK and JNK, disrupted MMP, facilitated the release of cytochrome $c$ and AIF into cytoplasm, activated capase-9 and caspase-3, and led to apoptosis of the A549 cells. As a result, HY may offer potential as a useful and beneficial natural agent against lung cancer.

\section{Acknowledgements}

The present study was supported by Scientific and Technologic Innovation Action of Shanghai Municipal Science and Technology Commission (grant no. 15401971800).

\section{References}

1. Zhang J, Liu J, Chen J, Li X, Wu Y, Chen H, Wu W, Zhang K and $\mathrm{Gu} \mathrm{L}$ : Angiotensin receptor blockers (ARBs) reduce the risk of lung cancer: A systematic review and meta-analysis. Int J Clin Exp Med 8: 12656-12660, 2015.

2. Qiu L, Lan L, Feng Y, Huang Z and Chen Y: Pulmonary actinomycosis imitating lung cancer on (18)F-FDG PET/CT: A case report and literature review. Korean J Radiol 16: 1262-1265, 2015.

3. Dong QZ, Wang Y, Tang ZP, Fu L, Li QC, Wang ED and Wang EH: Derlin-1 is overexpressed in non-small cell lung cancer and promotes cancer cell invasion via EGFR-ERK-mediated up-regulation of MMP-2 and MMP-9. Am J Pathol 182: 954-964, 2013.

4. Rao JS, Gondi C, Chetty C, Chittivelu S, Joseph PA and Lakka SS: Inhibition of invasion, angiogenesis, tumor growth and metastasis by adenovirus-mediated transfer of antisense uPAR and MMP-9 in non-small cell lung cancer cells. Mol Cancer Ther 4: 1399-1408, 2005.

5. Yue W, Ming QL, Lin B, Rahman K, Zheng CJ, Han T and Qin LP: Medicinal plant cell suspension cultures: Pharmaceutical applications and high-yielding strategies for the desired secondary metabolites. Crit Rev Biotechnol 36: 215-232, 2016.

6. $\mathrm{Ku}$ SK, Zhou W, Lee W, Han MS, Na M and Bae JS: Anti-inflammatory effects of hyperoside in human endothelial cells and in mice. Inflammation 38: 784-799, 2015.

7. Sukito A and Tachibana S: Isolation of hyperoside and isoquercitrin from Camellia sasanqua as antioxidant agents. Pak J Biol Sci 17: 999-1006, 2014.

8. Zhang J, Zhao F, Yu X, Lu X and Zheng G: Pharmacokinetics of eupalinolide A, eupalinolide B and hyperoside from Eupatorium lindleyanum in rats by LC/MS/MS. J Chromatogr B Analyt Technol Biomed Life Sci 995-996: 1-7, 2015. 
9. Yan Y, Feng Y, Li W, Che JP, Wang GC, Liu M and Zheng JH: Protective effects of quercetin and hyperoside on renal fibrosis in rats with unilateral ureteral obstruction. Exp Ther Med 8: 727-730, 2014

10. Al-Mahdi R, Babteen N, Thillai K, Holt M, Johansen B Wetting HL, Seternes OM and Wells CM: A novel role for atypical MAPK kinase ERK3 in regulating breast cancer cell morphology and migration. Cell Adh Migr 9: 483-494, 2015.

11. Jung HG, Kim HH, Paul S, Jang JY, Cho YH, Kim HJ, Yu JM, Lee ES, An BJ, Kang SC and Bang BH: Quercetin-3-O- $\beta$-dglucopyranosyl-( $1 \rightarrow 6)-\beta$-d-glucopyranoside suppresses melanin synthesis by augmenting p38 MAPK and CREB signaling pathways and subsequent cAMP down-regulation in murine melanoma cells. Saudi J Biol Sci 22: 706-713, 2015.

12. Chang D, Wang YC, Bai YY, Lu CQ, Xu TT, Zhu L and Ju S: Role of P38 MAPK on MMP activity in photothrombotic stroke mice as measured using an ultrafast MMP activatable probe. Sci Rep 5: 16951, 2015.

13. Huo YN, Chen W and Zheng XX: ROS, MAPK/ERK and PKC play distinct roles in EGF-stimulated human corneal cell proliferation and migration. Cell Mol Biol (Noisy-le-grand) 61: 6-11, 2015.

14. Ong JY, Yong PV, Lim YM and Ho AS: 2-Methoxy1,4-naphthoquinone (MNQ) induces apoptosis of A549 lung adenocarcinoma cells via oxidation-triggered JNK and p38 MAPK signaling pathways. Life Sci 135: 158-164, 2015.
15. Bu HQ, Cai K, Shen F, Bao XD, Xu Y, Yu F, Pan HQ, Chen CH, Du ZJ and Cui JH: Induction of apoptosis by capsaicin in hepatocellular cancer cell line SMMC-7721 is mediated through ROS generation and activation of JNK and p38 MAPK pathways. Neoplasma 62: 582-591, 2015.

16. Lee HH, Park C, Jeong JW, Kim MJ, Seo MJ, Kang BW, Park JU, Kim GY, Choi BT, Choi YH and Jeong YK: Apoptosis induction of human prostate carcinoma cells by cordycepin through reactive oxygen species-mediated mitochondrial death pathway. Int J Oncol 42: 1036-1044, 2013.

17. Hsieh YJ, Chang CJ, Wan CF, Chen CP, Chiu YH, Leu YL and Peng KC: Euphorbia formosana root extract induces apoptosis by caspase-dependent cell death via Fas and mitochondrial pathway in THP-1 human leukemic cells. Molecules 18: 1949-1962, 2013.

18. Niemi NM and MacKeigan JP: Mitochondrial phosphorylation in apoptosis: Flipping the death switch. Antioxid Redox Signal 19: $572-582,2013$. 